\title{
SUBAPROVEITAMENTO DO DICIONÁRIO POR ALUNOS DO ENSINO FUNDAMENTAL DE JACAREZINHO-PR
}

\section{Dictionary Underutilization by Elementary School Students}

\author{
Rogério Aparecido DUARTE - UENP ${ }^{1}$ \\ Fernando Moreno da SILVA - UENP ${ }^{2}$
}

RESUMO: A lexicografia pedagógica tem destacado o papel do dicionário como instrumento pedagógico no ensino e na aprendizagem da língua. Com esse desenvolvimento da lexicografia, a questão que se levanta é: houve alguma mudança na percepção dos alunos em relação à importância do dicionário para o aprendizado da língua? O propósito deste artigo é tentar responder a essa questão. Para isso, foi proposta a aplicação de questionários junto a alunos de duas escolas públicas de ensino fundamental do município de Jacarezinho-PR. O questionário mostrou que o dicionário é pouco usado e subutilizado, ficando restrito apenas na maioria das vezes à consulta de significado e de ortografia. Isso demonstra que todo potencial do dicionário como ferramenta pedagógica deixa de ser explorado, confirmando assim a suposição de que o ensino do léxico pelo dicionário em sala de aula é insuficiente e em muitas escolas praticamente inexistente.

PALAVRAS-CHAVE: Lexicografia pedagógica; Dicionário; Ensino.

ABSTRACT: The pedagogical lexicography highlights the role of the dictionary as an educational tool in teaching and learning the language. With this development of lexicography, a question arises: was there any change in the perception of the students about the importance of the dictionary for language learning? The purpose of this article is to try to answer this question. For this, it proposed the application of questionnaires to students from two public schools in the city of Jacarezinho-PR. The questionnaire showed that the dictionary is little used and underutilized, being restricted only to the meaning of consultation and spelling. This demonstrates that the dictionary potential as a pedagogical tool is not exploited, thus confirming the assumption that the teaching of vocabulary by the dictionary in the classroom is insufficient or underused.

KEYWORDS: Pedagogical lexicography; Dictionary; Teaching.

\section{INTRODUÇÃO}

\footnotetext{
${ }^{1}$ Mestre em Letras pelo Programa de Mestrado Profissional em Letras (PROFLETRAS/UENP/CCP). Professor da rede estadual de ensino.

${ }^{2}$ Doutor em Linguística (UNESP/Araraquara) e docente da Universidade Estadual do Norte do Paraná (UENP/Campus Jacarezinho).
} 
Considerando a importância da língua como meio de comunicação e acervo de cultura, o estudo do léxico se torna um poderoso instrumento para que o aluno desenvolva um domínio progressivo da leitura, da escrita e da oralidade, o que pode potencializar sua autonomia nos estudos e em suas interações sociais. Por isso, é importante o emprego adequado do vocabulário para produzir sentidos, descrever com clareza e confiança suas colocações nos diferentes contextos comunicativos. Nesse sentido, o uso do dicionário é uma ferramenta pedagógica de grande valor para o ensino e a aprendizagem da língua portuguesa, pois possui recursos importantes para reforçar os conteúdos e as propostas de abordagem do ensino do léxico em sala de aula.

É nesse cenário que os estudos lexicográficos cada vez mais vêm discutindo questões que tratam da relação entre os conhecimentos teóricos sobre o léxico e as práticas pedagógicas envolvidas no seu ensino, apontando caminhos para que se faça o bom uso do dicionário nas aulas de língua portuguesa, como Krieger (2012, p. 9) sugere:

Usá-lo, saber usá-lo, é uma das condições necessárias para usufruir de toda a potencialidade de um idioma, ao se expressar num texto ou ao compreender o que um texto expressa. Daí seu valor como instrumento no ensino e no aprendizado da língua materna, não só como um sistema fechado em suas regras, mas como um manancial aberto à criação expressiva de novos signos e formas que se dá em todos os níveis, da literatura às canções, à imprensa, ao uso popular, às novas ciências e tecnologias, sempre se renovando, sem limite de tempo ou abrangência.

O desenvolvimento de atividades com vocabulário mostra-se promissora para o desenvolvimento de uma competência textual significativa. Antunes (2012, p. 162) complementa que trabalhar com o acervo lexical da língua ainda pode desenvolver nos alunos as competências que lhes serão úteis no exercício diário de sua vida social e de sua atuação no mercado de trabalho, além de levá-los a compreender os sentidos de se poder dispor da linguagem, em sua multifuncionalidade interativa.

Como se vê nesse preâmbulo, a lexicografia ganhou espaço considerável, sobretudo no campo da educação. O que vem sendo chamado de "lexicografia pedagógica" (XATARA; BEVILACQUA; HUMBLÉ, 2008) tem destacado o papel do dicionário como instrumento pedagógico no ensino e na aprendizagem da língua. Isso tem refletido nas dissertações, nas teses e no mercado editorial (CARVALHO; 
BAGNO, 2011; DAMIM, 2005; DURÃO, 2010; MORAES, 2007; MÜLLER; CAMILOTTI; BATISTA, 2014; RANGEL; BAGNO, 2006) ${ }^{3}$. Com todo esse movimento, surgiu uma questão: com o desenvolvimento da lexicografia, houve alguma mudança na percepção dos alunos em relação à importância do dicionário para o aprendizado da língua? A lexicografia de fato tem sido pedagógica?

O propósito deste artigo foi tentar responder a essa questão. Para isso, foram aplicados questionários junto a alunos de duas escolas públicas estaduais de Ensino Fundamental do município de Jacarezinho- $\mathrm{PR}^{4}$ para verificar o conhecimento deles em relação ao uso de dicionários impresso ou eletrônico. São alunos do $8^{\circ}$ ano do ensino fundamental do Colégio Estadual Luiz Setti e alunos do $9^{\circ}$ ano do Colégio Estadual Rui Barbosa, todos com idade entre 13 e 17 anos. Tal questionário foi pensado e formulado com base nas sugestões de Welker (2008, p. 1-17). A aplicação do questionário faz parte de etapa inicial de pesquisa que está sendo desenvolvida junto ao Programa de Mestrado Profissional em Letras da Universidade Estadual do Norte do Paraná, campus de Cornélio Procópio 5 .

\section{LEXICOLOGIA E LEXICOGRAFIA}

Nascida no âmbito da linguística, a Lexicologia tem por objetivo o estudo científico do acervo de palavras de um determinado idioma: situa-se numa intersecção linguística que absorve informações advindas de caminhos diversos, ou seja, da fonética e da fonologia; da semântica; da morfologia; da sintaxe e das situações comunicativas, ou seja, da pragmática (GUERRA; ANDRADE, 2012, p. 230).

Para isso, ela procura investigar e determinar a origem, a forma e o significado das palavras que constituem o acervo lexical de um determinado idioma, bem como o seu uso na comunidade de seus falantes. Assim, através da lexicologia torna-se possível observar e descrever cientificamente as unidades léxicas de uma comunidade linguística.

\footnotetext{
${ }^{3}$ Essas referências são apenas algumas obras representativas. Não se trata, portanto, de uma relação exaustiva.

${ }^{4}$ Antes de aplicar o questionário, foram colhidos termos de consentimento e de assentimento de pais e alunos envolvidos na pesquisa, além do termo de autorização do diretor de escola para coleta de dados nas duas escolas.

${ }^{5}$ Título provisório da dissertação: “A construção de verbetes com base em letra de música: uma proposta pedagógica".
} 
Enquanto a Lexicologia se preocupa em estudar e descrever o léxico de uma língua, a lexicografia tem como finalidade o estudo e a elaboração de obras lexicográficas: a lexicologia analisa a estrutura e o funcionamento das unidades do léxico; a lexicografia se preocupa em registrar tais unidades num produto final (dicionário, glossário, banco de dados, etc.), pressupondo que o trabalho lexicográfico se configure dentro de uma ciência aplicada.

Ao analisar e registrar o acervo lexical de uma língua, a lexicografia assume um papel de grande relevância, pois além de preservar o idioma de uma determinada comunidade linguística, ainda sistematiza um conjunto de conhecimentos adquiridos e produzidos socialmente para que de forma estruturada e objetiva possam ser transmitidos entre culturas diferentes e também de geração em geração.

Para Borba (2003) a lexicografia pode ser vista sob duplo aspecto:

(i) como técnica de montagem de dicionários, ocupa-se de critérios para seleção de nomenclaturas ou conjunto de entradas, de sistemas definitórios, de estruturas de verbetes, de critérios para remissões, para registro de variantes etc.; (ii) como teoria, procura estabelecer um conjunto de princípios que permitam descrever o léxico (total ou parcial) de uma língua, desenvolvendo uma metalinguagem para manipular e apresentar as informações pertinentes (BORBA, 2003, p. 15).

Como técnica, a lexicografia levanta dados, faz estudo das unidades lexicais de uma língua e estabelece critérios para organizá-las no dicionário; enquanto teoria, procura refletir sobre o uso, tipos e problemas encontrados nas obras lexicográficas. Cabe ressaltar que a lexicografia teórica também recebe o nome de metalexicografia, abrangendo o estudo de problemas ligados à elaboração de dicionários, a critica dos dicionários, a pesquisa da historia da lexicografia, a pesquisa do uso de dicionários e ainda a tipologia (MORAES, 2007, p.19).

A lexicografia, grosso modo, nasce com a necessidade do homem de registrar os acontecimentos que faziam parte de seu cotidiano, sendo tão antiga quanto às pinturas rupestres. Durão (2010, p. 17) observa que "ao trazer à tona as pinturas rupestres, estamos trazendo concomitantemente os primórdios da escrita e, em consequência, a gênese dos dicionários.". Desde o surgimento da escrita propriamente dita, a lexicografia vem se aperfeiçoando e acompanhando a evolução das sociedades, tornando-se uma das grandes responsáveis pela transmissão de conhecimentos acumulados entre culturas e um dos fatores essenciais para o avanço tecnológico entre os seres humanos. De acordo com Rangel e Bagno (2006, p.13-14), os dicionários, tais 
como os conhecemos, sugiram na Europa no final do século XV, possuindo propósitos diferentes: destinava-se a fazer equivalência entre o vocabulário do latim (ou grego) com as línguas modernas que iam se tornando independentes, para que os alunos das universidades tivessem acesso aos textos clássicos. Por outro lado, era preciso também sistematizar, ao lado das recentes gramáticas das línguas modernas, a língua dos povos dominados para que se pudesse impor a língua do dominador. Quanto às obras lexicográficas em língua portuguesa, as primeiras dignas de nome, segundo Biderman (2001, p. 17), foram: "Vocabulário Português-Latino", de Raphael Bluteau (17121728); "Dicionário da Língua Portuguesa", de Antônio de Moraes Silva (1. ed. 1789, 2. ed. 1813).

\title{
LEXICOGRAFIA PEDAGÓGICA
}

Ao se aproximar dos domínios do ensino e da aprendizagem de línguas, a lexicografia se especializou na chamada "lexicografia pedagógica". Ainda não há um consenso entre teóricos a respeito desse termo. Krieger (2012, p. 22) informa que:

\begin{abstract}
A lexicografia pedagógica é uma nova área de conhecimento que vem crescendo no mundo todo em razão da consciência sobre o importante papel dos dicionários para o ensino/aprendizagem de línguas. Mesmo considerando que todo e qualquer dicionário é um instrumento didático, pois traz inúmeras informações sobre a língua e a cultura, a Lexicografia Pedagógica tem como fundamento de que é preciso adequar o tipo de dicionário aos distintos projetos de ensino/níveis de aprendizagem.
\end{abstract}

Nesse aspecto, o Brasil vem avançando paulatinamente, já que as ações governamentais implementadas desde 2002 decidiram incluir as obras lexicográficas entre os materiais didáticos no contexto do Programa Nacional do Livro Didático (PNLD). Com essa medida, o PNLD, além de retomar o valor pedagógico de gramáticas e dicionários, propondo remodelá-los da forma mais próxima possível das situações e demandas do ensino e aprendizagem formais, também incluiu a consulta a dicionários como objeto de ensino e aprendizagem escolar. Em consequência disso, os dicionários receberam um valor nunca antes manifesto pelo governo brasileiro. Krieger (2012, p.23) salienta que em 2006, para o PNLD, foram adotadas diretrizes inovadoras ao serem abertas inscrições para três tipos distintos de dicionários, a saber:

1. Dicionário de tipo 1: apresenta de 1.000 a 3.000 verbetes e sua proposta lexicográfica está voltada para familiarização do alfabetizando com o gênero dicionário; 
2. Dicionário de tipo 2: apresenta o mínimo de 3.500 e o máximo de 10.000 verbetes e sua proposta lexicográfica direciona-se àqueles alunos que estão em fase de consolidação do domínio da escrita;

3. Dicionário de tipo 3: com no mínimo 19.000 verbetes e no máximo 35.000 sua proposta lexicográfica orienta-se pelas características de um dicionário padrão, adequadas aos alunos das ultimas series do primeiro segmento do ensino fundamental.

Como se pode notar, o avanço nessa área vem ganhando espaço e, ao incluir os dicionários no PNDL, o MEC liga a ideia de tipo de dicionário a objetivos de ensino, fazendo-se cumprir os fundamentos básicos da lexicografia pedagógica. Esse cenário intensificou os estudos em torno da lexicografia, pois esses tipos de dicionários se tornaram alvo de muitas discussões e estão cada vez mais presentes em artigos, dissertações e teses, o que fez com que a produção de conhecimento em torno da lexicografia e das obras lexicográficas apresentasse novas propostas para o ensino e aprendizagem do léxico no universo escolar.

\section{O DICIONÁRIO}

Um dos principais fatores que diferenciam o ser humano de outras espécies animais, como se sabe, é a capacidade de se comunicar e consequentemente poder trocar, registrar e fazer o resgate de informações, o que lhe confere a possibilidade de utilizar um sistema quase inesgotável de signos linguísticos, os quais fazem alusão aos significados das coisas que o homem pode perceber e quando esses signos se combinam estruturalmente, representam ideias, conceitos e descrições dessas tais coisas. A condição para que a comunicação se estabeleça está centrada na palavra, a qual determina os contextos de cada significado, possibilitando assim a interação entre os indivíduos de uma mesma comunidade ou entre indivíduos de comunidades diferentes. Todo esse acervo de palavras pode ser encontrado nos dicionários, o que faz com que esse tipo de obra seja um lugar profícuo para se aprender, processar e utilizar os conhecimentos ali sistematizados em torno de um determinado idioma.

De acordo com Aulete (GEIGER, 2011, p. 495), a definição para a palavra dicionário é a seguinte:

[d]icionário (di.ci.o.ná.rio) sm 1 Obra que reúne em ordem alfabética, as palavras de uma língua ou termos referentes a uma matéria específica, e descreve se significado, uso, etimologia etc., na mesma língua ou em outra (dicionário de cinema/de inglês) $2 \mathrm{O}$ conjunto de palavras ou termos reunidos 
nessa obra 3 Livro ou outro suporte que contém tais informações (dicionário eletrônico) (...) (AULETE, 2011, p. 495).

Como se pode observar pela definição, a abrangência de significado da palavra dicionário é bem ampla e logo se percebe que esta obra de referência se desdobra em vários tipos de dicionários que se destinam a diferentes propósitos e a diferentes públicos. Por esse caminho, Krieger (2012, p. 17) observa que:

Há uma grande variedade de obras que recebem o nome de dicionário: dicionário bilíngue, terminológico, escolar, infantil entre outros. Cada um possui características especificas, entretanto, o dicionário de língua é o mais típico de todos. É o mais geral e mais abrangente no registro do léxico de um idioma, apresenta informações gramaticais, semânticas e outras relacionadas ao uso das palavras. São aspectos que justificam por que é também identificado como 'dicionário padrão'.

Os dicionários são elaborados pelos dicionaristas, que sempre procuram formular uma descrição plausível para o léxico. Para isso, recolhem informações importantes no universo cultural dos usuários da língua, informações essas provenientes tanto de saberes popular quanto de saberes especializado.

\footnotetext{
Nesse sentido, os conhecimentos que o dicionário põe à nossa disposição são "de segunda mão", o que faz dele um gênero didático (e/ou de divulgação) por excelência. Numa definição de átomo, não vamos encontrar a definição dada por um físico, mas uma síntese, uma tradução de definições tecnicamente especializadas. Da mesma forma, nos conhecimentos culturalmente compartilhados, as explicações não são as que obteríamos perguntando a respeito a alguém na rua, mas uma versão mais formal e sistematizada. Portanto, também por esse motivo, os dicionários não são sempre - nem devem pretender ser - a "última palavra" sobre os itens que registram (RANGEL; BAGNO, 2006, p. 23).
}

Os dicionários de língua estão estruturados em uma dupla estrutura: a macroestrutura e a microestrutura. A macroestrutura está organizada em três partes principais: As páginas iniciais, o corpo do dicionário e as páginas finais. Nas páginas inicias geralmente se encontram: a apresentação, listas e abreviaturas e instruções para o uso da obra. É na apresentação que estão as informações necessárias para a compreensão e o bom aproveitamento da proposta lexicográfica, os princípios organizacionais, o público-alvo e metodologia da seleção dos itens lexicais: são essas informações que vão delinear o perfil da obra. O corpo do dicionário, também chamado de nomenclatura, é constituído por todas as palavras catalogadas. Essas palavras encontram-se dispostas em ordem alfabética, na forma de lema, seguidas das 
informações a elas relacionadas, formando esse conjunto (palavra-entrada mais informações) o verbete. Por fim, as páginas finais, com referências, índice remissivo e outros dados, vem complementar a obra.

É bom lembrar que o dicionário pode variar, ficando a cargo de o dicionarista incluir ou excluir tais informações de acordo com o público que ele deseja atingir.

\section{APLICAÇÃO DO QUESTIONÁRIO}

Para verificar se os desenvolvimentos lexicográfico e metalexicográfico repercutiram em sala de aula, foram aplicados questionários junto a alunos de ensino fundamental para verificar o conhecimento deles em relação ao uso de dicionários. $\mathrm{O}$ questionário, composto de 10 questões, foi aplicado em duas escolas: 34 alunos do $8^{\circ}$ ano do Colégio Estadual Luiz Setti e 20 alunos do $9^{\circ}$ ano do Colégio Estadual Rui Barbosa, ambos situados na cidade de Jacarezinho-PR, pertencentes à rede pública de ensino público do estado do Paraná. Segue balanço da investigação.

\section{ALUNOS DO COLÉGIO ESTADUAL LUIZ SETTI}

Pergunta 1- A que série você pertence? Idade?

Pertencem ao $8^{\circ}$ ano e possuem idade entre 13 e 17 anos.

Pergunta 2 - Você já consultou um dicionário?

Todas as respostas foram positivas sobre já ter usado ou consultado um dicionário pelo menos uma vez na vida.

Pergunta 3 - Quais tipos de dicionário você conhece?

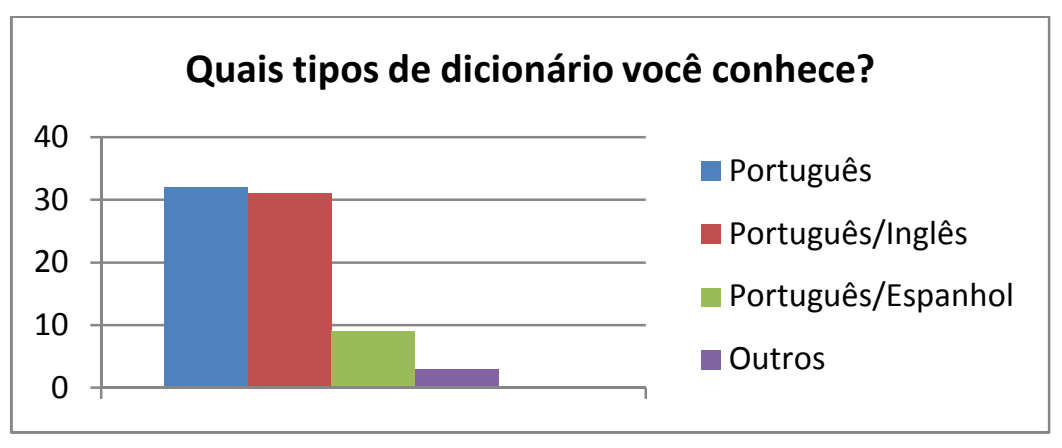

Quanto a conhecer os tipos de dicionário, os alunos na sua grande maioria, como se pode perceber no gráfico, reconhecem os tipos utilizados no universo escolar e apenas na área das disciplinas direcionadas ao ensino de línguas. Porém, no caso do 
campo, outros 2 alunos citaram dicionário de matemática e os demais citaram o nome do dicionário (Aurélio, Houaiss, Saraiva, Etc.).

Pergunta 4 - Você possui dicionário em casa? Se sim, quais?

Dos 34 alunos, somente 14 possuem dicionário em casa, sendo dicionários de uso escolar de Português e Português/Inglês.

Pergunta 5 - Você tem o hábito de consultar dicionário? Se sim, para que finalidade? Caso não use, por quê?

Os dados se repetem na mesma proporção da anterior: 14 têm o hábito de usar dicionário, indicando que os alunos que possuem o dicionário em casa o consultam com mais frequência. Assim justificam a finalidade do uso:

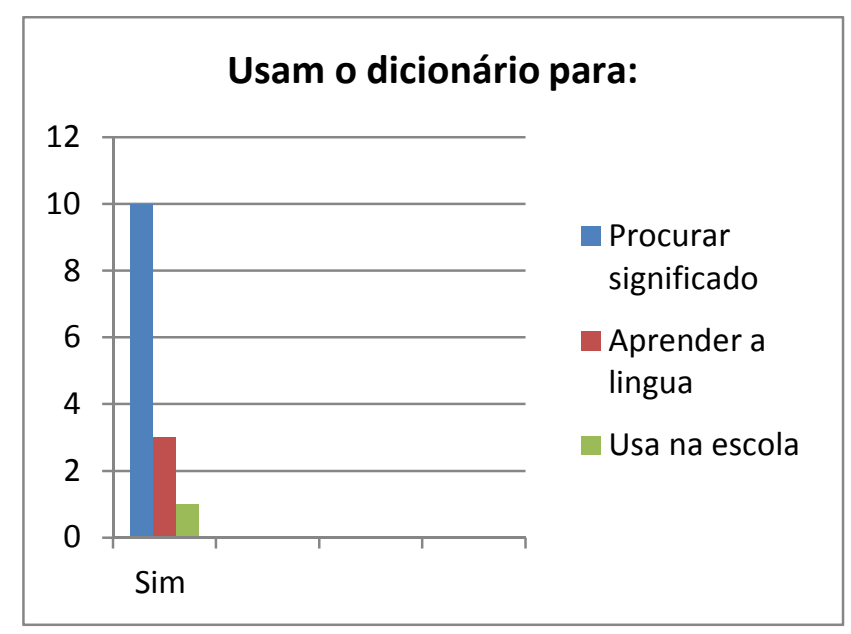

Aqui reside uma das grandes preocupações da lexicografia quanto à subutilização do dicionário, pois ao se prender ao significado da palavra ou consultá-lo apenas para sanar dúvidas sobre a ortografia do vocábulo, todo potencial pedagógico do dicionário sofre uma grande ameaça; dos 14 que disseram ter o hábito de usar o dicionário, 10 o utilizam apenas para a busca do significado, 3 deles fizeram uma colocação mais sensata ao responderem que usam para aprender a língua e apenas 1 disse que usa só na escola quando solicitado. Vamos às justificativas do não uso do dicionário: 
REVISTA X, volume12, n.1, p $121-137,2017$

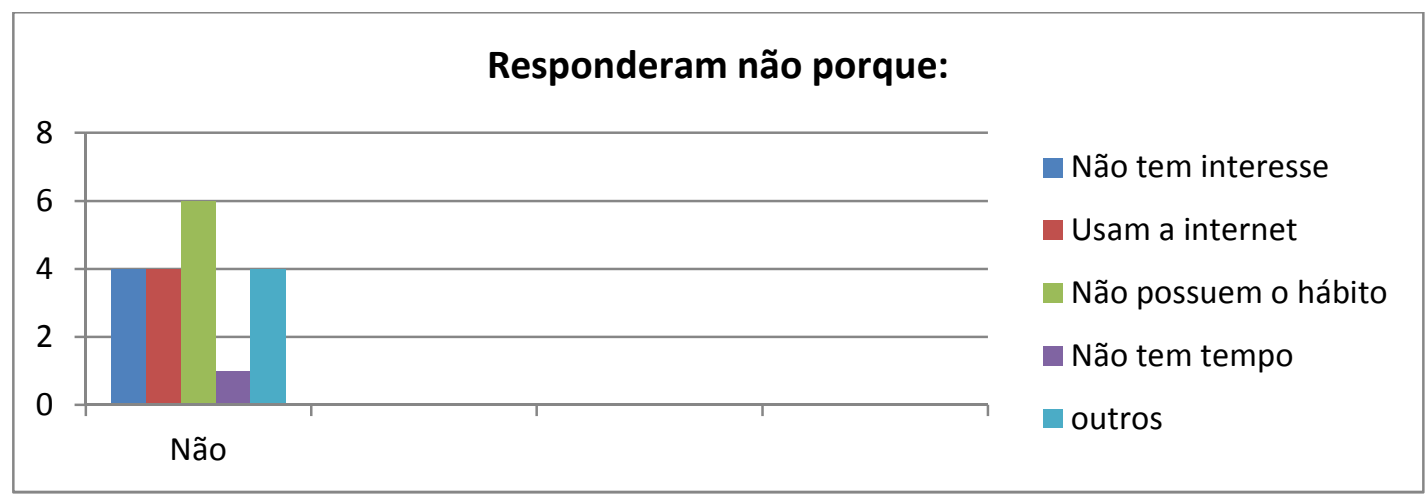

Dos vinte alunos que declararam que não possuem o hábito de usar o dicionário, seis deles disseram que não têm interesse, quatro alegaram que usam a internet, outros quatro não possuem o hábito e um disse que lhe falta tempo, enquanto os quatro restantes não souberam responder.

Pergunta 6- Seus professores já recomendaram o uso de dicionário em sala de aula?

Os alunos foram unânimes ao afirmar ter recebido recomendações para usar o dicionário em sala de aula.

Pergunta 7 - Já teve alguma explicação em sala de aula de como usar o dicionário? Se sim, quais?

Dos 34 alunos, 24 disseram ter tido orientação para o uso correto do dicionário em sala de aula, enquanto 10 afirmaram que nunca tiveram nenhuma orientação. Os que responderam "sim" alegaram que as explicações foram as seguintes:

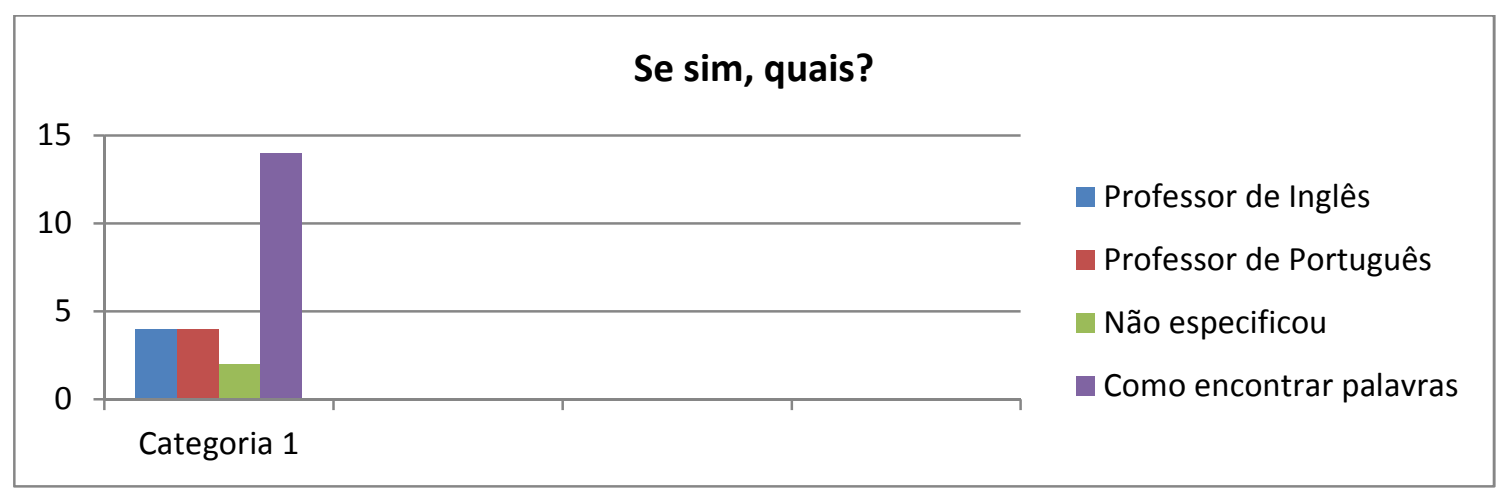

Quatro alunos disseram ter recebido instruções do professor de inglês, outros quatro do professor de português, dois deles não especificaram o tipo de orientação e os catorze restantes alegaram ter recebido orientações de como encontrar palavras, mas não revelaram o professor nem a disciplina. Cabe aqui uma ressalva, os únicos professores especificados, como se pode notar, são os professores de línguas, confirmando assim a 
suposição de que outras disciplinas, como geografia, ciências, história, matemática, etc., deixam de explorar o potencial dessa obra tão significante para todas as áreas do conhecimento.

Pergunta 8 - Usa o dicionário impresso (de papel) ou eletrônico? Por quê?

A maioria dos alunos (24) usa o dicionário impresso; isso se justifica pela escola estar localizada em uma área carente da periferia da cidade de Jacarezinho. Apenas sete disseram usar o dicionário eletrônico, enquanto outros dois afirmaram fazer uso dos dois suportes. E quanto ao porquê do uso, as justificativas foram as seguintes: um dos alunos informou que só sabia usar o impresso, dois deles disseram não possuir internet, nove responderam que é mais fácil de ser utilizado, três pontuaram que é o único que tem na escola, um aluno disse que é o mais acessível, dois disseram que é o único que têm em casa, enquanto os outros seis não opinaram. Dos sete alunos que afirmaram usar o dicionário eletrônico, seis alegaram ser mais fácil e um ser mais prático. Os que disseram fazer uso dos dois suportes não souberam responder.

Pergunta 9 - Quais suas criticas em relação aos dicionários? Cite problemas e dificuldades.

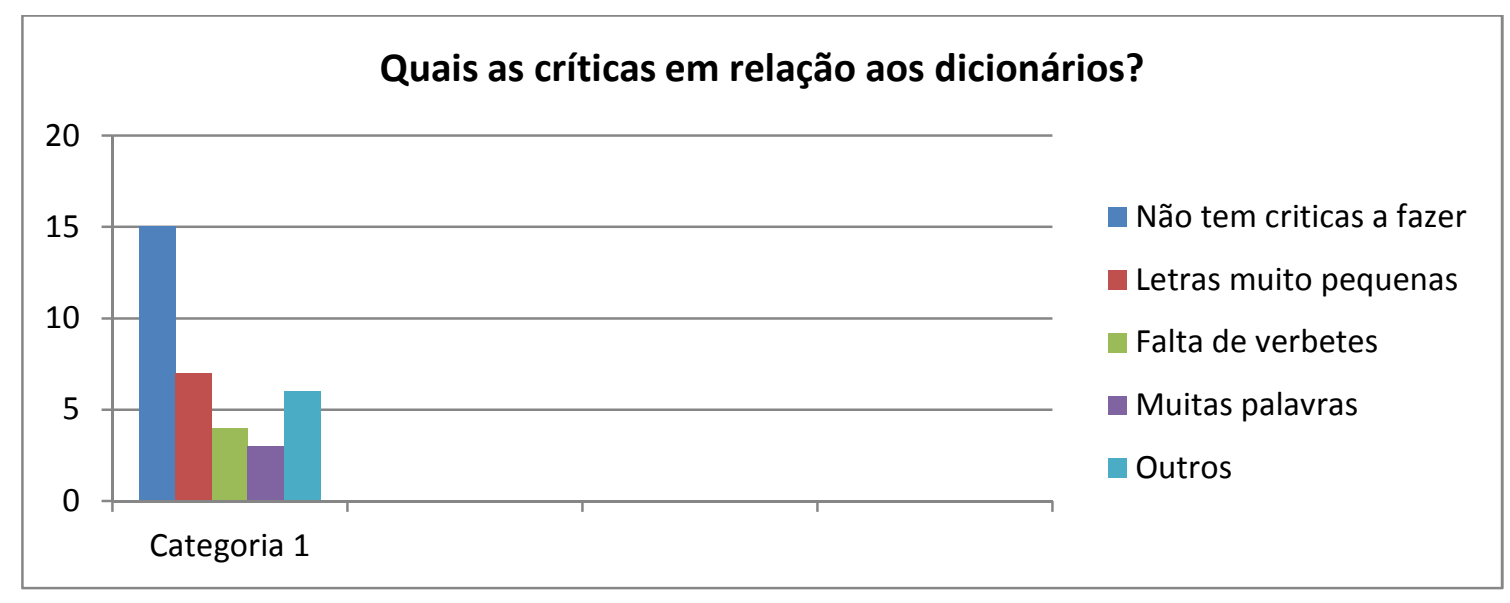

Quanto às criticas feitas pelos alunos aos dicionários, metade dos trinta e quatro informou que não havia críticas a fazer; do restante, alguns criticaram o tamanho das letras, dizendo que deviam ser maiores, outros disseram que faltam verbetes, uns reclamaram que o dicionário tem muitas palavras e os demais não souberam responder. Pergunta 10 - O que gostaria de ver melhorado no dicionário? 
REVISTA X, volume12, n.1, p121-137, 2017

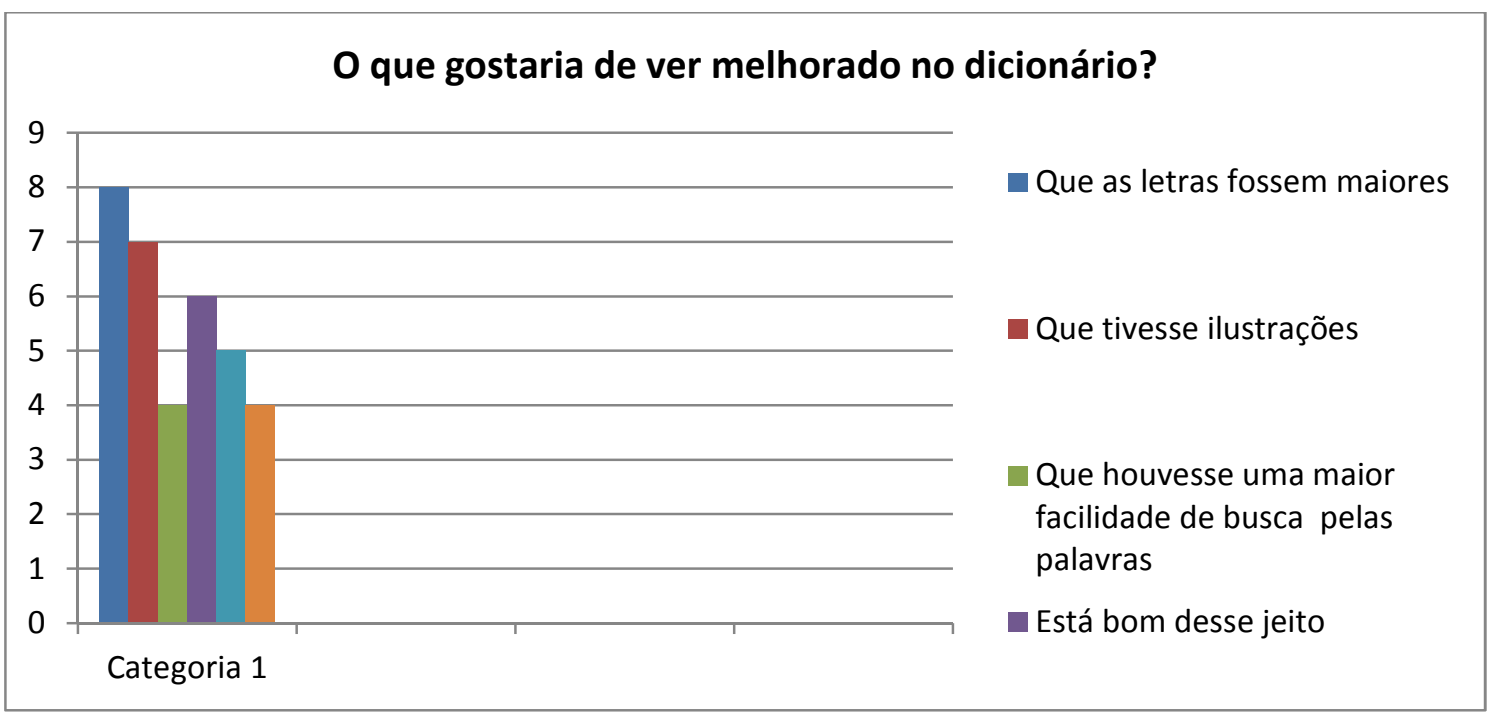

As respostas se mostram bem variadas, como se pode notar no gráfico, indo desde a reinvindicação por letras maiores, passando por exigências de ilustrações, até maior facilidade de busca pelas palavras. E seis dos alunos informaram que o dicionário está bom do jeito que é.

\section{ALUNOS DO COLÉGIO RUI BARBOSA}

Pergunta 1- A que série você pertence? Idade?

Pertencem ao $9^{\circ}$ ano e também possuem idade possuem idade entre 13 e 17 anos.

Pergunta 2 - Você já consultou um dicionário?

Pela popularidade do dicionário e pelo fato de os alunos estarem inseridos no universo escolar, esse resultado já era de se esperar: 100\% dos alunos já usaram o dicionário pelo menos uma vez na vida.

Questão 3 - Quais tipos de dicionário você conhece?

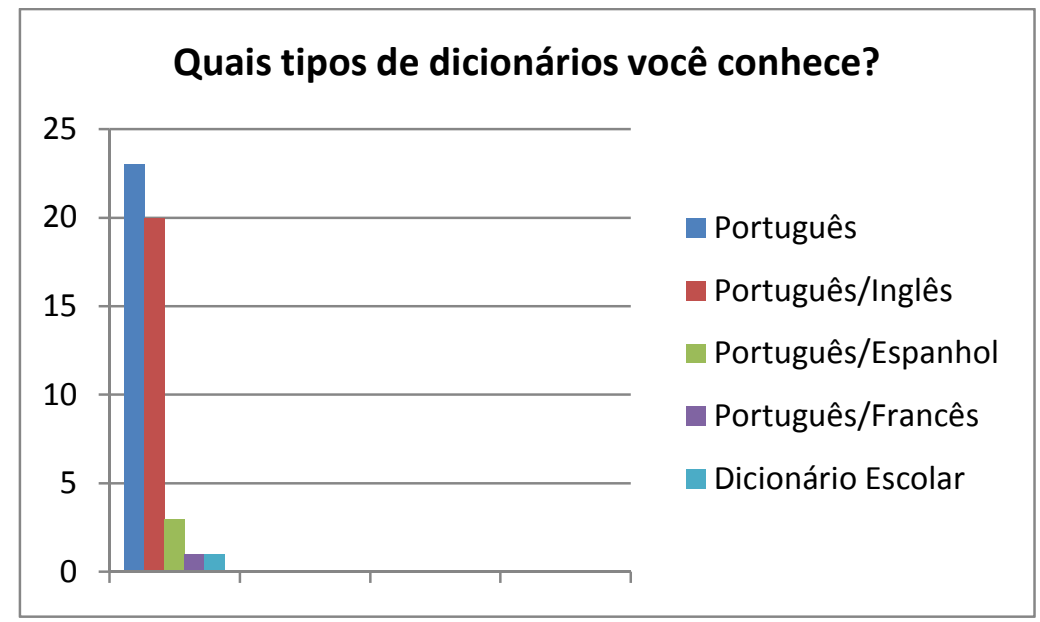


Também aqui, os tipos de dicionários conhecidos pelos alunos são aqueles utilizados para auxiliá-los no aprendizado de línguas, tanto da materna quanto das estrangeiras.

Pergunta 4 - Você possui dicionário em casa? Se sim, quais?

Sobre possuir dicionário em casa, dos vinte alunos questionados, 10 disseram possuir; os outros 10 não possuem. Os dicionários que os alunos têm em casa são de português ou português/inglês.

Pergunta 5 - Você tem o hábito de consultar dicionário? Se sim, para que finalidade?

Caso não use, por quê?

Enquanto apenas seis alunos dizem ter o hábito de usar o dicionário, os outros 14 dizem não utilizá-lo habitualmente. Quanto à finalidade, para os que o utilizam, são as seguintes: cinco alunos afirmam que utilizam na escola, podendo-se inferir que utilizam apenas quando algum professor solicita; somente um aluno disse que utiliza o dicionário para conhecer palavras. Os que não têm o hábito de utilizar o dicionário não justificaram suas respostas.

Pergunta 6 - Seus professores já recomendaram o uso de dicionário em sala de aula?

Dezenove alunos informaram que já receberam recomendações para usar o dicionário em sala de aula, e um admitiu que nunca recebeu tal recomendação.

Pergunta 7 - Já teve alguma explicação em sala de aula de como usar o dicionário?

Se sim, quais?

Dos 20 alunos, somente cinco dizem ter recebido instruções para o uso do dicionário em sala de aula, reafirmando, assim, que estudos realizados em torno do uso do dicionário em sala de aula são insuficientes se conduzidos de maneira equivocada; quanto a justificativas sobre que tipo de explicação recebeu, quatro responderam que foram orientados a como procurar palavras e um citou a ordem alfabética. Não especificaram a disciplina em que esta explicação aconteceu.

Pergunta 8 - Usa o dicionário impresso (de papel) ou eletrônico? Por quê?

Doze alunos afirmaram que utilizam o dicionário impresso, cinco usam o eletrônico, um faz uso de ambos e dois alunos não usam nenhum dos dois.

Pergunta 9 - Quais suas críticas em relação aos dicionários? Cite problemas e dificuldades. 


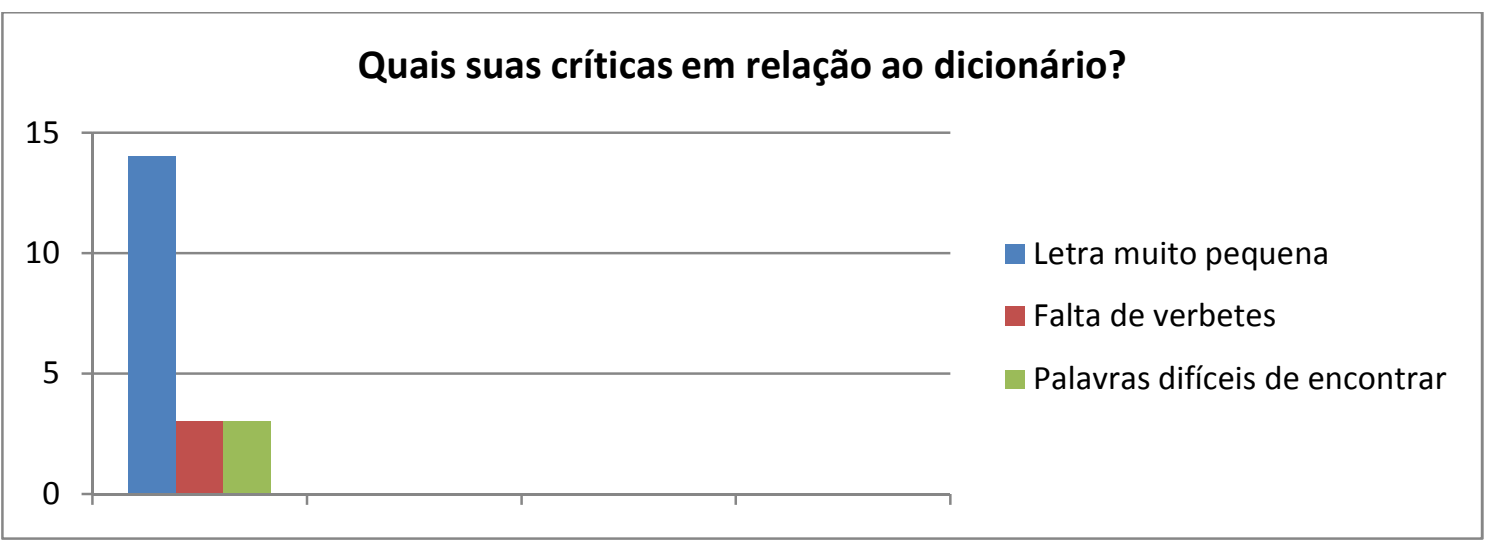

Como demonstra o gráfico acima, dos 20 alunos questionados, 14 fazem críticas ao tamanho da letra, os quais acham que deveriam ser maiores, quatro deles reclamam da dificuldade de se encontrar as palavras e três alunos acham que é preciso aumentar o número de verbetes.

Pergunta 10 - O que gostaria de ver melhorado no dicionário?

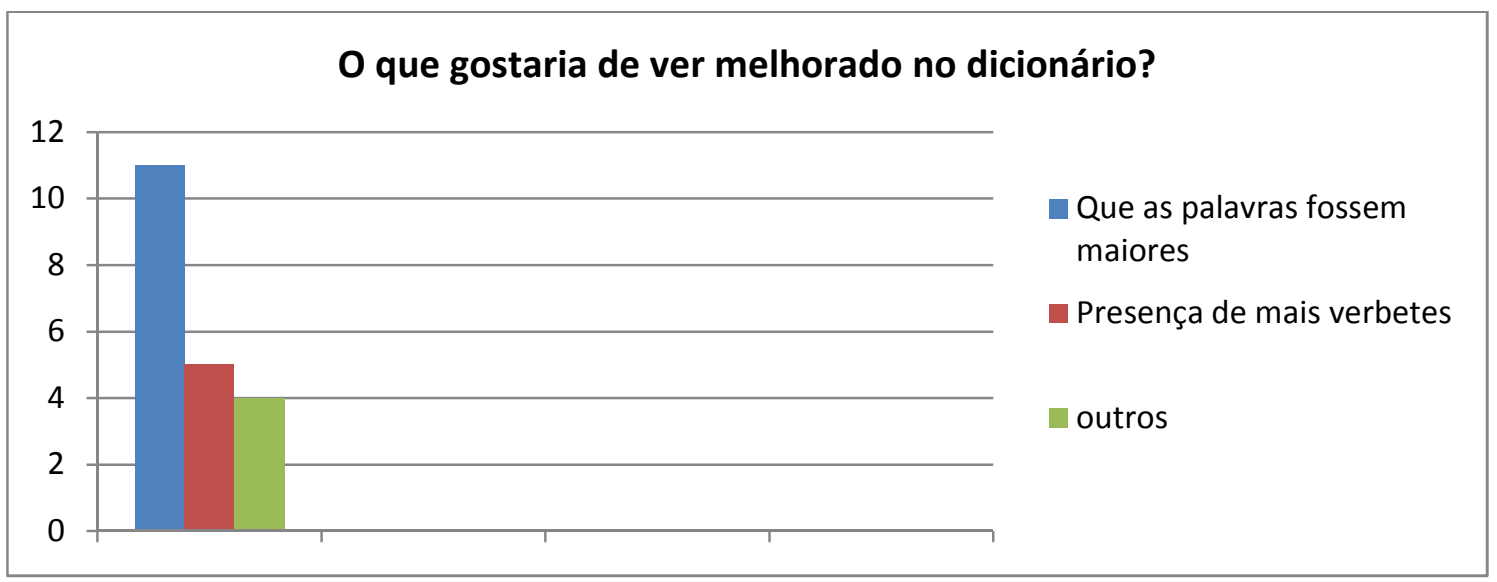

De acordo com o gráfico, nota-se que a principal reivindicação dos alunos, que pedem aumento das letras dos dicionários, está atrelada à falta de conhecimento sobre essa obra lexicográfica; é mais um indício da falta de atenção ao ensino do léxico em sala de aula. Cinco alunos insistem na inclusão de mais verbetes no corpo do dicionário, enquanto os demais não souberam responder.

Diante do exposto, nota-se que as respostas dos alunos evidenciam que, apesar de todos os alunos pesquisados já terem consultado o dicionário, grande parte não possui o hábito de utilizá-lo com frequência; quando o utiliza para buscar alguma informação, essa busca se restringe ao significado ou para confirmar a ortografia de uma palavra. Dessa forma, percebe-se que todo potencial do dicionário como ferramenta 
pedagógica deixa de ser explorado, confirmando assim a suposição de que o ensino do léxico pelo dicionário em sala de aula é insuficiente e em muitas escolas praticamente inexistente.

\section{CONSIDERAÇÕES FINAIS}

Ainda que tenha havido grande avanço dos estudos na área da lexicografia, sobretudo quanto à abordagem do léxico no ensino da língua materna, haja vista as pesquisas nos programas de pós-graduação e as publicações do mercado editorial, a aplicação dos questionários nas duas escolas supracitadas mostrou que o potencial pedagógico do dicionário não tem sido adequadamente explorado em sala de aula. No Colégio Luiz Setti, por exemplo, apenas $41 \%$ têm o hábito de usar o dicionário, restringindo o uso à consulta de significado na maioria das vezes. No Colégio Rui Barbosa, são 30\% que costumam usar apenas quando estão na escola.

Como se vê, o uso do dicionário continua se restringindo maiormente à busca significado ou à confirmação da ortografia de uma palavra. Outras finalidades, como aponta Welker (2006) ao longo de seu livro, são ignoradas, como pronúncia, sinônimos, antônimos, notas de uso (marcação de uso), etimologia, classe de palavra, prazer ou cultura, gramática, exemplos de uso, unidades fraseológicas, separação silábica, etc.

A subutilização do dicionário, como afirma Höfling (2006, p. 325), "se deve não só à complexidade dos códigos utilizados nas obras lexicográficas, mas também a uma possível inabilidade dos professores de entender os códigos e fornecer a seus alunos as chaves para a consulta.”. Esse cenário de ignorância lexicográfica revela a necessidade urgente de incluir a Lexicografia no currículo dos cursos de Letras e Pedagogia para conscientizar os professores da relevância do dicionário como instrumento pedagógico. Com professores aptos, os alunos poderão receber instruções para manejar e explorar o potencial pedagógico do dicionário, essa obra tão importante para o ensino/aprendizagem da língua materna, desenvolvendo competências lexical, linguística, discursiva e comunicativa.

\section{REFERÊNCIAS}

ANTUNES, I. O território das palavras: estudo do léxico em sala de aula. São Paulo: Parábola Editorial, 2012. 
GEIGER, P (org.) Novíssimo Aulete: dicionário contemporâneo da língua portuguesa. Rio de Janeiro: Lexikon, 2011. 1488 p. [75 mil verbetes]

BIDERMAN, M. T. C. As Ciências do Léxico. ln.: OLIVEIRA, A. M. P. P.; ISQUERDO, A. N. As ciências do léxico: Lexicologia, Lexicografia, Terminologia. 2 ed. Campo Grande: Editora UFMS, 2001, p. 13-22.

BLUTEAU, R. Vocabulario portuguez \& latino: aulico, anatomico, architectonico ... Coimbra: Collegio das Artes da Companhia de Jesus, 1712 - 1728. 8 v.

BORBA, F. S. Organização de dicionários: uma introdução à lexicografia. São Paulo: UNESP, 2003.

CARVALHO, O. L. S.; BAGNO, M. (orgs.). Dicionários escolares: políticas, formas e usos. São Paulo: Parábola Editorial, 2011. 165 p.

DAMIM, C. P. Parâmetros para uma avaliação do dicionário escolar. 2005. $230 \mathrm{f}$. Dissertação (Mestrado em Estudos da Linguagem). Instituto de Letras, Universidade Federal do Rio Grande do Sul, Porto Alegre, 2005.

DURÃO, A. B. A. B. (org.). Vendo o dicionário com outros olhos. Londrina: UEL, 2010.

GUERRA, M. M.; ANDRADE, K. S. O léxico sob perspectiva: contribuições da Lexicologia para o ensino de línguas. Domínios de Lingu@gem, Uberlândia, v. 6, n. 1, p. $226-241,1^{\circ}$ Semestre 2012.

HÖFLING, C. Traçando um perfil de usuários de dicionários - estudantes de Letras com habilitação em língua inglesa: um novo olhar sobre dicionários para aprendizes e a formação de um usuário autônomo. 2006. 376 f. Tese (Doutorado em Linguística e Língua Portuguesa). Faculdade de Ciências e Letras, Universidade Estadual Paulista, Araraquara, 2006.

KRIEGER, M. G. Dicionário em sala de aula: guia de estudos e exercícios. Rio de Janeiro: Lexikon, 2012. 47.

MORAES, A. C. A utilização de dicionários de língua portuguesa em salas de aula do ensino fundamental. 2007. 107 f. Dissertação (Mestrado em Estudos Linguísticos).

Instituto de Biociências, Letras e Ciências Exatas, Universidade Estadual Paulista, São José do Rio Preto, 2007.

MÜLLER, A. F.; CAMILOTTI, F. P.; BATISTA, R. P. Dicionário na escola: manual didático para uso em sala de aula. São Paulo: Editora do Brasil, 2014.

RANGEL, E. O.; BAGNO, M. Dicionários em sala de aula. Brasília: Ministério da Educação, Secretaria da Educação Básica, 2006. 
SILVA, A. M. Diccionario da lingua portugueza - recompilado dos vocabularios impressos ate agora, e nesta segunda edição novamente emendado e muito acrescentado, por ANTONIO DE MORAES SILVA. Lisboa: Typographia Lacerdina, 1813.

WELKER, H. A. O uso de dicionários: panorama geral das pesquisas empíricas. Brasília: Thesaurus, 2006.

Sobre o uso de dicionários. In: CELSUL 2008 ( $8^{\circ}$ Encontro do Círculo de Estudos Lingüísticos do Sul), 2008. Porto Alegre. Anais do $8^{\circ}$ Encontro do CELSUL, 2008, p. 1-17.

XATARA, C.; BEVILACQUA, C.; HUMBLÉ, P. Lexicografia pedagógica: pesquisas e perspectivas. Florianópolis: UFSC/NUT, 2008. 